\title{
THERMOPHIIIC AND PATHOGENIC AMOEBAE FROM HOT SPRINGS IN WYOMING
}

\author{
William D. O'Dell \\ Department of Biology \\ University of Nebraska \\ Omaha \\ and \\ Robert F. Ramaley \\ Department of Biochemistry \\ University of Nebraska Medical Center \\ Omaha
}

\section{Objectives}

The long range goal of this research is to document the occurrence of pathogenic amoebae in thermal habitats that have been altered or disturbed by human activity. Immediate goals for this year included the development of reliable methods of detection for use in the field, the determination of the incidence and prevalence of thermophilic Naegleria in selected hot springs of Wyomingr and the investigation of potential natural sources of Naegleria. In addition, we initiated a cooperative project with Dr. A. J. Pinter to document the endoparasites of small mammals of the Grand Teton National Park.

\section{Methods}

The research is divided into two distinct phases. The first phase is the collection of samples, isolation and the preliminary identification of thermophilic/pathogenic Naegleria. The second phase is the more conventional laboratory studies to characterize the isolates and to perform microbiological and biochemical studies on those isolates of particular interest. Only a summary of the methods will be included here since a more detailed description may be found in the proposal.

The primary study site was the Huckleberry Hot Springs located just north of the Grand Teton National Park. The site consists of several springs that flow into Polecat creek. Additional sites included commercially developed springs such as Astoria Hot Springs and Granite Hot Springs as well as the undeveloped Kelly Warm Springs.

Isolation of Naegleria was accomplished by filtering water samples and placing the filters on the surface of non-nutrient agar plates that had been spread with a suspension of bacteria used as a food source. The plates were incubated at 45C and observed daily for the presence of amoeba plaques. When plaques appeared, a piece of agar with the amoebae was removed and transferred to a 
tissue culture flask containing $3.0 \mathrm{~mL}$ of sterile distilled water. These flasks were incubated at 37C and observed at 2, 4 and 24 hours for the presence of flagellates. The flasks permitted observation of the morphology of the amoebae and the determination of the presence of Elagellates without the need for preparing slides. It also serves well as a convenient transport container. A moebae isolated at $45 \mathrm{C}$ and forming flagellates at $37 \mathrm{C}$ are considered to be Naegleria. Soil and algal mat samples were treated in the same manner except that appropriate dilutions were made in sterile distilled water before spreading aliquots directly on the bacteria-seeded agar plates (2).

The isolates were initially identified on the basis of accepted morphological criteria. However, amoebae that appear morphologically identical, frequently demonstrate very diverse physiological and biochemical characteristics. Differences in some of these characteristics may be sufficient to recognize distinct strains or in some instances different species. Characterization of isoenzyme patterns is a widely used technique for the specific identification of these amoebae (1). This analysis also permits us to compare our new isolates with other isolates from many sources. This method of biochemical fingerprinting will tell us if the isolates are unique or if they are part of a cosmopoiltan species distribution.

A number of isolates have already been successfully adapted to various axenic (bacteria-free media as a first step in the characterization of the isoenzymes. The cells were harvested from the axenic media and divided into two samples. One sample was frozen for storage to maintain the strain while the other sample was lysed and then frozen until use in the isoemzyme analysis. The final identification by isoemzyme analysis should be completed in the Spring of 1986.

During the summer of 1985 we examined the intestinal contents of six animals, five Microtus montanus and one gopher, that were live trapped as part of a continuing study of small mammal populations in the Grand Teton National Park conducted by Dr. A. J. Pinter. The intestines were preserved in $10 \%$ formalin and the contents examined by phase contrast microscopy in wet mount preparations.

\section{Results}

A summary of the preliminary identification of the isolates based on morphological characteristics is shown in Table 1. Naegleria is the most frequently encountered genus in water samples where it accounted for $71 \%$ of a total of 158 isolates and in soil samples where it represented $42 \%$ of a total of 98 isolates. With the exception of the samples taken from an unnamed spring on Polecat Creek, the newly described thermophilic amoebae, Willaertia magna was isolated only from soil samples in the United States. Species of Acanthamoeba, Hartmannella and Echinoamoeba were isolated primarily from soil samples or from water samples at lower temperatures. No amoebae were isolated from the swimming pool at Astoria Hot Springs or from Kelly Warm Springs.

Initial examination of the intestinal contents of the voles and gopher failed to demonstrate any parasites. However, subsequent examination of the intestinal 
Table 1. Amoeba isolates from hot springs.

\begin{tabular}{|c|c|c|c|c|}
\hline Site & $\begin{array}{l}\text { Temp } \\
\text { (C) }\end{array}$ & Naegleria & Vahlkampfia & Willaertia \\
\hline \multicolumn{5}{|l|}{ Huckleberry Hot Springs } \\
\hline Swimmiing Pool & 31 & 6 & $<1$ & $<1$ \\
\hline Artificial Pool & 40 & 21 & $<1$ & $<1$ \\
\hline Creek & $35-39 *$ & 17 & 1 & $<1$ \\
\hline Runoff Channel & $45-46$ * & 29 & $<1$ & $<1$ \\
\hline Soil/Artificial Pool & & 2 & 2 & $<1$ \\
\hline Soil/Runoff Channel & & 30 & 1 & 7 \\
\hline \multicolumn{5}{|l|}{ Granite Hot Springs } \\
\hline Sediment Pool & 40 & 1 & $<1$ & $<1$ \\
\hline Swimming Pool & 37 & $<1$ & $<1$ & $<1$ \\
\hline Runoff Channel & $36-37 *$ & 4 & 1 & $<1$ \\
\hline \multicolumn{5}{|l|}{ Polecat Creek Springs } \\
\hline Unknown Spring & 44 & 5 & 3 & 1 \\
\hline Artificial Pool \#1 & 41 & 3 & 7 & 1 \\
\hline Artificial Pool \#2 & 34 & 4 & 4 & 1 \\
\hline Creek & 21 & $<1$ & $<1$ & \\
\hline Campground Springs & 45 & 3 & $<1$ & $<1$ \\
\hline Campground Runoff & & & & \\
\hline Channel & 44 & 9 & $<1$ & $<1$ \\
\hline \multicolumn{5}{|l|}{ Campground Artificial } \\
\hline Pool & 43 & 10 & $<1$ & $<1$ \\
\hline \multicolumn{5}{|l|}{ Soil/Campground } \\
\hline Artificial Pool & & 9 & 4 & 8 \\
\hline
\end{tabular}

*Data combined from two samples 
mucosae, revealed a heavy infection of Giardia sp. as well as an isoporan in two of the voles and in the gopher. Careful re-examination of the intestinal contents failed to show either trophozoites or cysts of Giardia.

\section{Conclusions}

We: have modified existing methods (1) to develop a relatively fast and simple technique for the field isolation and identification of thermophilic amoebae. When this method is applied to water and soil samples from hot springs, Naegleria sp. are the most frequently isolated amoebae. Specific identification of the isolates by isoenzyme analysis will allow us to identify pathogens and to determine the potential of human exposure to these organisms.

More study will be necessary to determine the significance of the presence of Giardia in voles and gophers to both humans and to populations of these small mammals.

\section{Literature Cited}

De Jonckheere, J. 1981. Naegleria australiensis sp. nov., another pathogenic Naegleria from water. Protistologica 17:423-429.

O'Dell, W. D. 1979. Isolation, enumeration and identification of amoebae from a Nebraska lake. J. Protozool. 26:265-269. 